\title{
Multiple Myeloma-IgM (not Waldenstrom Macroglobulinemia)
}

National Cancer Institute

\section{Source}

National Cancer Institute. Multiple Myeloma-IgM (not Waldenstrom Macroglobulinemia). NCI Thesaurus. Code C70610.

The heavy chain, IgM, of the immunog lobulin is defective. This finding is seen in other lymphocytic/plasmacytic disorders as well, including Waldenstrom macroglobulinemia. 